\title{
Motivação de alunos do ensino fundamental: estudo de duas realidades culturais
}

\author{
Sandra Maieski \\ Universidade Estadual de Londrina - Londrina - PR - Brasil \\ Katya Luciane de Oliveira \\ Universidade Estadual de Londrina - Londrina - PR - Brasil \\ Andrea Carvalho Beluce \\ Universidade Estadual de Londrina - Londrina - PR - Brasil \\ Sueli Édi Rufini \\ Universidade Estadual de Londrina - Londrina - PR - Brasil
}

\section{Resumo}

A motivação no contexto escolar é um tema muito discutido na contemporaneidade da educação em diferentes espaços e culturas. O presente estudo tratou do constructo motivação à luz da Teoria da Autodeterminação e buscou avaliar a motivação para aprender de crianças dos primeiros anos do ensino fundamental de duas realidades culturais distintas: Brasil e Chile. Participaram da pesquisa 528 crianças, sendo 268 brasileiras e 260 chilenas que responderam a dois questionários sobre motivação. O método utilizado foi para análise dos dados foi do tipo descritivo com delineamentos de levantamento e correlacional. Os resultados evidenciaram que a maioria das crianças, dos dois contextos investigados, se revelou motivada para aprender. A discussão dos resultados considerou as implicações educacionais das duas realidades culturais.

Palavras-chave: Motivação íntrinseca; motivação extrínseca; ensino fundamental.

\section{Motivation of elementary school students: study of two cultural realities}

\begin{abstract}
The motivation in the school context is a much discussed theme in the contemporaneity of education in different places and cultures. The present study dealt with the motivation construct in the light of the Self Determination Theory and sought to evaluate the motivation to learn from the first years of elementary school in two different cultural realities: Brazil and Chile. A total of 528 children participated in the study, of which 268 were Brazilian and 260 were Chilean who answered two questionnaires on motivation. The method used was for descriptive data analysis with survey designs and correlational. The results showed that most of the children in the two contexts investigated were motivated to learn. The discussion of the results considered the educational implications of the two cultural realities.
\end{abstract}

Keywords: Intrinsic motivation; extrinsic motivation; elementary school.

\section{Motivación de alumnos de la enseñanza primaria: estudio de dos realidades culturales}

\footnotetext{
Resumen

La motivación en el contexto escolar es un tema muy discutido en la contemporaneidad de la educación en diferentes espacios y culturas. En el presente estudio se trató del constructo motivación a la luz de la Teoría de la Autodeterminación y se buscó evaluar la motivación para aprender de niños de los primeros años de la enseñanza primaria de dos realidades culturales distintas: Brasil y Chile. Participaron de la investigación 528 niños, siendo 268 brasileñas y 260 chilenas que respondieron a dos cuestionarios acerca de la motivación. El método utilizado fue para análisis de los datos fue del tipo descriptivo con delineamientos de levantamiento y correlacional. Los resultados evidenciaron que la mayoría de los niños, de los dos contextos investigados, se reveló motivada para aprender. La discusión de los resultados considerólas implicaciones educacionales de las dos realidades culturales.
}

Palabras clave: Motivación íntrinseca; motivación extrínseca; enseñanza secundaria. 


\section{Introdução}

Autores como Pintrich e Schunk (2002) e Bzuneck e Guimarães (2010) consideram que motivar os alunos para aprender não é tarefa fácil. A clareza quanto à importância da motivação, notadamente no campo educacional formal, despertou em diversos pesquisadores (Deci \& Ryan, 2000, Osborne \& Jones, 2011; Rufini, Bzuneck, \& Oliveira, 2012; Perassinoto, Boruchovitch, \& Bzuneck, 2013; Bzuneck, Megliato, \& Rufini, 2013; Pereira, 2015; Gniewosz, Eccles, \& Noak, 2015; Chen \& cols., 2015; Wigfield \& cols., 2015, dentre outros) a curiosidade de investigar as relações que se estabelecem entre este constructo e a aprendizagem.

A motivação, no contexto específico da sala de aula, apresenta características peculiares que a diferenciam de outras atividades humanas igualmente dependentes de motivação como, por exemplo, o esporte, conforme destacam Reeve, Deci e Ryan (2004) e Bzuneck (2009). Sob essa perspectiva, estudos como os de Rufini e cols. (2012), Perassinoto e cols. (2013) e Pereira (2015) evidenciaram a relação entre a motivação e a aprendizagem escolar, destacando que alunos motivados envolvem-se ativamente nas tarefas propostas. Por outro lado, um aluno desmotivado faz o mínimo na realização de uma atividade e/ou desiste facilmente quando as tarefas lhe parecem um pouco mais exigentes. A ausência da motivação representa, portanto, queda de investimento pessoal e de qualidade nas tarefas escolares resultando, consequentemente, numa aprendizagem deficiente ou escassa (Rufini \& cols., 2012).

Os avanços teóricos nas áreas da psicologia e da educação, referentes à motivação dos alunos, advêm principalmente do conhecimento obtido de estudos que se fundamentaram em teorias sociocognitivistas, dentre as quais se destaca a Teoria da Autodeterminação (Deci \& Ryan, 2000). Bzuneck e Guimarães (2010) observam que o eixo central da teoria da Autodeterminação parte da afirmação de que os seres humanos são capazes de se autorregularem. Sendo assim, tal teoria propõe que as necessidades psicológicas básicas de autonomia (a pessoa percebe-se autora da ação, capaz de realizar uma determinada atividade voluntariamente e/ou de decidir sobre suas ações), de competência (percepção de eficácia ao se relacionar com o ambiente; com a capacidade e habilidade para a superação de desafios) e de vínculo (estabelecimento de vínculos confiáveis com outras pessoas, os quais permitem ao indivíduo sentir-se emocionalmente envolvido e seguro em relacionamentos que requerem atenção) são determinantes pelo modo como as pessoas sentem, pensam e se comportam (Bzuneck \& Guimarães, 2010; Bzuneck \& cols., 2013).

O continuum proposto pela Teoria da Autodeterminação representa a evolução do comportamento e retrata a motivação para aprender como um processo cíclico. Nesta perspectiva, Rufini e cols. (2012) observam que é possível distinguir tipos diversos de regulação do comportamento, os quais variam de acordo com o nível de autonomia ou autodeterminação percebido. Assim, identifica-se graus de autodeterminação na motivação extrínseca.
No continuum da regulação do comportamento figuram aqueles elementos compreendidos desde a desmotivação, ou seja, a ausência de intenção para agir, até a motivação intrínseca. Entre esses dois polos, encontra-se a motivação extrínseca apresentada em quatro tipos, conforme apontam Reeve e cols. (2004) e Bzuneck e Guimarães (2010): por regulação externa (caracteriza-se pela realização de uma determinada tarefa com a finalidade de obter os benefícios externos à atividade ou de evitar situações desagradáveis), por regulação introjetada (a realização de uma atividade é motivada pelo sentimento de culpa, pelo rompimento social que ausência sua realização pode acarretar ou, ainda, para atender as instâncias ligadas à autoestima), por regulação identificada (o indivíduo se identifica com as exigências ou com as regras que the são apresentadas na realização de uma atividade) e por regulação integrada (a pessoa assume a tarefa por escolha pessoal, sem nenhuma forma de coação, pois é considerada algo importante, assimilada ao próprio self).

Considerando-se que a motivação é um dos fatores mais determinantes para o êxito ou o fracasso no contexto escolar (Deci \& Ryan, 2000; Reeve \& cols., 2004, Rufini \& cols. 2012), pesquisas realizadas em âmbito nacional (Guimarães, Bzuneck, \& Oliveira, 2011; Zenorini, Santos, \& Monteiro, 2011; Fernandes \& Silveira, 2012; Rufini \& cols., 2011; Zambon \& Rose, 2012; Bzuneck \& cols., 2013; Maieski, Oliveira, \& Bzuneck, 2013; Perassinoto \& cols., 2013; Martinelli, 2014; Oliveira, Maieski, Beluce, Oliveira, \& Santos, 2014 e outras) e internacional (Osborne \& Jones, 2011; Valenzuela \& cols., 2012; Silva-Peña, García, Tapia, Llancafil, \& Carreño, 2013; Muñoz \& Valenzuela, 2014; Chen \& cols., 2015; Pereira, 2015; Gniewosz \& cols., 2015; Paulino, Sá, \& Silva, 2015; Wigfield \& cols., 2016, dentre outros), reafirmam a importância de se investigar esse tema.

Tendo em vista a complexidade do construto motivação (Bzuneck, 2009) e a sua relevância à aprendizagem do aluno, considera-se relevante a realização de pesquisas interculturais que se proponham a investigar a motivação para aprender, objetivando ampliar o conhecimento sobre essa temática e as implicacões advindas de diferentes variáveis contextuais. Logo, o presente estudo se propôs a investigar a motivação para aprender de crianças, estudantes do ensino formal, em dois cenários socioculturais distintos: Brasil e Chile.

No que concerne à literatura chilena, cabe relatar que este estudo levantou o número de pesquisas científicas, realizadas no período de 2005 a 2015, que investigaram a motivação para aprender do aluno do ensino fundamental. $\mathrm{O}$ levantamento indicou que ainda é incipiente os estudos chilenos que tratam de temática, posto que somente seis estudos foram encontrados: Fernández González, Martinez-Conde Beluzan e Melipillán Araneda (2009), Rosas, Pérez-Salas e Olguín (2010), Villalobos, Mujica, González-Pienda, Núñez Pérez e Rosário (2009); Valenzuela e cols. (2012), Silva-Peña e cols. (2013) e Muñoz e Valenzuela (2014). Diante do exposto, a sequência do texto apresenta o estudo, do tipo descritivo e com delineamentos de levantamento e correlacional, que 
investigou a motivação de alunos matriculados em escolas brasileiras e chilenas.

\section{Método}

Inicialmente, esclarece-se que a pesquisa foi aprovada pelo Comitê de Ética da Universidade Estadual Paranaense, sob protocolo número 189/10. Por ocasião do envio ao Comitê de Ética, providenciou-se a autorização das instituições de ensino, privadas e públicas, no Brasil e no Chile. A coleta de dados realizada nas instituições de ensino privada, tanto no Brasil como no Chile, se deu em escolas confessionais de uma rede de ensino que possui unidades escolares em diversos países. No Brasil, a coleta junto às escolas brasileiras, públicas e privadas, ocorreu no estado do Paraná. Vale ainda relatar que, a escola pública chilena pesquisada apresentava semelhanças com a escola pública brasileira quanto às condições socioeconômicas.

Nesse contexto, participaram 528 alunos dos anos iniciais do ensino fundamental matriculados em quatro escolas: uma privada e uma pública do Brasil e uma privada e uma pública do Chile. A idade média dos estudantes foi de 7 anos e 8 meses $(D P=1,3)$, sendo a idade mínima 5 anos $(n=9,1,7 \%)$ e a máxima, 11 anos $(n=2,0,4 \%)$. O gênero masculino representou $15,9 \%(n=84)$ da amostra e o feminino $84,1 \%(n=444)$. Quanto aos participantes do Chile, foram contabilizados 130 alunos $(24,6 \%)$ de uma escola privada da capital e 130 (24,6\%) de uma escola pública do sul do país. No Brasil, participaram 138 alunos $(26,1 \%)$ de uma escola privada e 130 (24,6\%) de uma escola pública, ambas situadas na região sul do país.

A escolha das escolas se deu por conveniência. Os estudantes do $1^{\circ}$ ano do Chile representaram 24,24\% ( $n=63$ ) da amostra, os do $2^{\circ}$ e $3^{\circ}$ anos representaram exatamente o mesmo percentual: $26,53(n=69)$ e os do $4^{\circ}$ ano $22,7 \%(n=59)$. No caso do Brasil, os alunos do $1^{\circ}$ ano representaram $17,54 \%$ ( $n=47)$ da amostra, os do $2^{\circ}$ ano compuseram 19,77\% ( $\left.n=53\right)$, os do $3^{\circ}$ ano caracterizaram $12,7 \% \quad(n=34)$, os da $3^{a}$ série representaram 22,38\% ( $n=60)$ da amostra e $27,61 \%(n=74)$ foram expressados pelos os alunos da $4^{\mathrm{a}}$ série.

Foram utilizadas e adaptadas para esta pesquisa duas medidas de motivação, quais sejam: o Questionário de Continuum Infantil (Guimarães \& cols., 2011) e a Escala de Motivação e Estratégias para o Aprendizado. A primeira medida de motivação foi organizada com o intuito de avaliar a qualidade motivacional de estudantes do ensino fundamental. O referido instrumento apresentava 25 itens, distribuídos em 5 subescalas, sendo que para cada item a criança deve atribuir uma nota de 1 a 5 . Os índices de consistência interna entre os itens de cada subescala, medidos pelo Alfa de Cronbach, foram: desmotivação=0,85, motivação extrínseca por regulação externa $=0,67$, por regulação introjetada=0,76, por regulação identificada=0,88 e motivação intrínseca=0,81. A adaptação realizada dos itens da versão em português para a versão em espanhol pode ser observada no exemplo a seguir: "Por que venho à escola? Não sei, acho que não tem nada para se fazer na escola”. "¿Por qué vas al colegio? No sé, creo que no hay nada para hacer en el colegio".

A Escala de Motivação e Estratégias para o Aprendizado (Oliveira \& cols., 2014) é uma medida composta tanto por itens inerentes a comportamentos motivados da criança para aprender, como por questões associadas às estratégias de aprendizagem utilizadas por elas. $O$ instrumento apresenta 29 itens com questões relativas aos motivos dos alunos para estudar e as estratégias para o aprendizado, com três alternativas de respostas: sim, às vezes, nunca. A opção 'sempre' vale 3 pontos, a opção 'às vezes', 2 e a opção 'nunca', 1. Convém esclarecer que o presente estudo utilizou somente os itens da referida escala concernentes à motivação. Novamente, foram realizadas adaptações das questões deste instrumento para a língua espanhola: "Estudo porque gosto" (sempre, às vezes, nunca); "Estudio porque me gusta" (siempre, a veces, nunca).

Após as adequações, as duas medidas foram encaminhadas para a tradução em espanhol e aplicou-se a técnica de back translation. No Brasil foi realizado, para um grupo de alunos do $1^{\circ}$ ano, um estudo-piloto com a Escala de Motivação e Estratégias para o Aprendizado. Em virtude da dificuldade demonstrada pelas crianças em responder a escala, somente o Questionário de Continuum Infantil foi utilizado com crianças brasileiras do $1^{\circ}$ ano. No Chile, também foi realizado um teste piloto que demonstrou a necessidade da adequação de alguns vocábulos de ambos os instrumentos.

\section{Resultados}

Os dados foram organizados em planilha e submetidos às estatísticas descritiva e inferencial, visando atender os objetivos propostos. Responderam à Escala de Motivação e Estratégias para o Aprendizado 90,7\% $(n=479)$ do total da amostra. Os alunos do $1^{\circ}$ ano das duas escolas avaliadas no Brasil, a privada e a pública, não responderam a esta escala (conforme já relatado). Quanto ao número de respondentes do Questionário de Continuum Infantil, este obteve variações. Isso se deve ao fato de que este instrumento de medida está dividido em subescalas, situação que permitiu que algumas crianças deixassem questões sem resposta e/ ou marcassem duas respostas ocasionando, consequentemente, a anulação do item.

O resultdo advindo da média de pontos obtida com a Escala de Motivação e Estratégias para o Aprendizado, na versão de 14 itens, indicou o valor de 31,8 $(D P=3,8)$. A pontuação mínima foi de $5(n=1,0,2 \%)$ a máxima de $41 \quad(n=1$, $0,2 \%)$. O percentual $12,3 \%(n=65)$ representou o maior grupo com 34 pontos. Os números, concernentes à quantidade de crianças que respondeu a cada uma das subescalas do Questionário de Continuum Infantil, aos dados de média, ao desvio-padrão, à pontuação máxima e à mínima, podem ser observados na Tabela 1.

A verificação da motivação de alunos brasileiros e chilenos se deu a partir da somatória dos pontos obtidos com a Escala de Motivação e Estratégias para o Aprendizado e 
Tabela 1. Frequência (n), Variação Da Pontuação E Distribuição Das Médias, Desvios-Padrão, Pontuações Máxima E Mínima Em Cada Subescala.

\begin{tabular}{llccccc}
\hline Subescalas & $n$ & variação & média & $d p$ & mínima & máxima \\
\hline Desmotivação & 515 & $1-25$ & 7,4 & 3,8 & 5 & 25 \\
Regulação Externa & 513 & $1-25$ & 11,6 & 4,9 & 5 & 25 \\
Regulação Introjetada & 514 & $1-25$ & 13,7 & 5,2 & 5 & 5 \\
Regulação Identificada & 421 & $1-25$ & 23,4 & 2,7 & 5 & 25 \\
Motivação Intrínseca & 518 & $1-25$ & 22,7 & 3,5 & 5 \\
\hline
\end{tabular}

com as subescalas do Questionário de Continuum Infantil. $\mathrm{Na}$ Escala de Motivação e Estratégias para o Aprendizado, as crianças chilenas $(n=260)$ obtiveram, como média 32,3 pontos $(D P=3,5)$. Quanto aos resultados obtidos por alunos chilenos em cada subescala do Questionário de Continuum Infantil, os dados podem ser visualizados na Tabela 2.
A análise da Tabela 2 oportunizou observar que a maioria das crianças matriculadas na $1^{\text {a }}$ fase do ensino básico chileno apresenta o nível mais elevado da motivação extrínseca por regulação identificada e motivação intrínseca. A proporção é três vezes superior à desmotivação, ou seja, são crianças motivadas para aprender. Quanto à motiva-

Tabela 2. Frequência (n), Distribuição Das Médias E Desvios-Padrão Em Cada Subescala Obtida Por Alunos Chilenos.

\begin{tabular}{lccc}
\hline Subescalas & $\mathrm{n}$ & médias & $d p$ \\
\hline Desmotivação & 254 & 7,5 & 3,8 \\
Regulação externa & 254 & 12,0 & 4,8 \\
Regulação introjetada & 254 & 13,8 & 5,1 \\
Regulação identificada & 257 & 23,0 & 2,9 \\
Motivação intrínseca & 255 & 23,1 & 3,3 \\
\hline
\end{tabular}

Tabela 3. Frequência (n), Distribuição Das Médias E Desvios-Padrão Em Cada Subescala, Obtida Por Alunos Brasileiros.

\begin{tabular}{lccc}
\hline Subescalas & $n$ & média & $d p$ \\
\hline Desmotivação & 261 & 7,3 & 3,7 \\
Regulação externa & 259 & 11,3 & 5,07 \\
Regulação introjetada & 260 & 13,6 & 5,4 \\
Regulação identificada & 264 & 23,9 & 2,4 \\
Motivação intrínseca & 263 & 22,3 & 3,7 \\
\hline
\end{tabular}


ção dos alunos brasileiros ( $n=219)$, a soma da pontuação na Escala de Motivação e Estratégias para o Aprendizado revelou a média de 31,2 pontos $(D P=4,1)$. Os dados obtidos mediante o Questionário de Continuum Infantil podem ser vistos na Tabela 3.

Ao se compararem os dados da Tabela 2 (motivação dos alunos chilenos), com os indíces da Tabela 3 (motivação dos estudantes brasileiros), pode-se constatar resultados muito próximos, com diferenças dentro da mesma casa decimal. Da mesma forma que os alunos chilenos, os brasileiros demonstraram possuir qualidade motivacional para aprender, pois a proporção da pontuação na subescala motivação intrínseca revelou-se três vezes maior que a pontuação obtida na subescala desmotivação.

No intuito de explorar eventuais diferenças entre as crianças brasileiras e as crianças chilenas na motivação para aprender foi aplicado o teste $t$ de Student. Os dados evidenciaram diferença estatisticamente significativa na Escala de Motivação e Estratégias para o Aprendizado, considerando-se $t=2,942$ e $p=0,003$. Pela pontuação na referida escala, os alunos brasileiros se revelaram menos motivados $(M=31,2)$ que os alunos chilenos $(M=32,3)$. Também houve diferença nas subescalas motivação extrínseca por regulação identificada, considerando-se $t=-3,788$ e $p=0,001$ e na subescala motivação intrínseca, considerando-se $t=2,522$ e $p=0,012$. Segundo o teste $t$ de Student, os alunos brasileiros são mais motivados extrinsecamente por regulação identificada $(M=23,9)$ que os alunos chilenos $(M=23,0)$, enquanto que os alunos chilenos são mais motivados intrinsecamente $(M=23,1)$ do que os alunos brasileiros $(M=22,3)$.

Para averiguar diferenças na pontuação obtida nas escalas de motivação por tipo de escola, foi empregada a Análise de Variância (ANOVA). Os dados post-hoc de Tukey evidenciaram diferença estatisticamente significativa na Escala de Motivação e Estratégias para o Aprendizado considerando-se $F(3,475)=3,690, p=0,012$. Os dados do teste post-hoc de Tukey mostraram que a diferença $(p=0,011)$ na referida escala estava entre a escola privada do Brasil $(M=31,0)$ e a escola pública do Chile $(M=32,6)$.

No que se refere ao Questionário de Continuum Infantil, os dados levantados a partir da ANOVA revelaram que houve diferença entre as escolas na subescala motivação extrínseca por regulação identificada $F(3,517)=7,690$, $p=0,000$. O teste post-hoc de Tukey mostrou que a diferença $(p=0,000)$ estava entre as escolas privada do Brasil $(M=24)$ e Chile $(M=22)$. No Chile também houve diferença $(p=0,026)$ entre as escolas privada $(M=22,5)$ e pública $(M=23,4)$. Também pela ANOVA foi possível constatar diferença entre as escolas na motivação intrínseca $F(3,514)=5,291, p=0,001$. A diferença estatisticamente significativa $(p=0,001)$ se encontra entre a escola pública chilena $(M=23,7)$ e a escola pública brasileira $(M=21,9)$.

Usou-se a ANOVA para verificar possível diferença na motivação para aprender entre os anos escolares da realidade chilena da escola privada e da pública. Houve diferença estatisticamente significativa na Escala de Motivação e Estratégias para o Aprendizado, considerando-se $F(3,250)=4,552$, $p=0,032$, sendo que o teste post-hoc de Tukey apontou que a diferença $(p=0,0006)$ estava entre o $1^{\circ}$ ano $(M=32,6)$ e o $2^{\circ}(M=31,7)$. Em relação a pontuação advinda da Escala de Motivação e Estratégias para o Aprendizado, concernentes aos primeiros anos da educação básica chilena, os resultados indicaram diferenças estatisticamente significativas entre $01^{\circ}$ e o $2^{\circ}$ anos da primeira etapa da educação fundamental.

Também houve diferença apontada pela ANOVA no Questionário de Continuum Infantil na motivação extrínseca por regulação externa considerando-se $F(3,250)=8,472$, $p=0,000$. Nesse caso, o teste post-hoc de Tukey revelou que a diferença $(p=0,004)$ estava entre o $1^{\circ}$ ano $(M=12,7)$ e o $4^{\circ}$ $(M=10,5)$ e também houve diferença $(p=0,001)$ entre o $2^{\circ}$ ano $(M=13,9)$ e o $4^{\circ}(M=10,5)$.

No caso da motivação extrínseca por regulação introjetada a ANOVA indicou diferença, considerando-se $F(3,250)=10,209, p=0,000$. O teste post-hoc de Tukey mostrou diferença $\left(p=0,001\right.$, respectivamente) entre $01^{\circ}$ ano $(M=15,8)$ e os $3^{\circ}(M=12,5)$ e $4^{\circ}(M=11,7)$ anos. Também houve diferenças $(p=0,012$ e $p=0,001$, respectivamente) entre o $2^{\circ}$ ano $(M=15,1)$ e o $3^{\circ}$ e $4^{\circ}$ anos. A diferença na motivação intrínseca também foi observada pela ANOVA, considerando-se $F(3,251)=6,324, p=0,001$. O teste post-hoc de Tukey indicou diferenças $(p=0,002, p=0,011$ e $p=0,001$, respectivamente) entre o $1^{\circ}$ ano $(M=24,7)$ e os $2^{\circ}(M=22,6)$, $3^{\circ}(M=22,9)$ e o $4^{\circ}(M=22,3)$ anos.

No que se refere à motivação extrínseca por regulação externa e regulação introjetada, evidenciada mediante os dados, fica manifesto que os dois primeiros anos da educação básica chilena não possuem diferenças significativas entre si. Contudo, no que se refere à motivação intrínseca, é perceptível a diferença significativa entre o $1^{\circ}$ ano e todos os subsequentes, o que revela que o maior nível de motivação intrínseca se encontra no $1^{\circ}$ ano. Outro dado relevante, apontado pelo teste post-hoc de Tukey, refere-se ao fato de que não houve diferença estatisticamente significativa entre os $2^{\circ}, 3^{\circ}$ e $4^{\circ}$ anos quanto à motivação intrínseca.

Ainda com o intuito de verificar possível diferença na motivação para aprender entre os anos/séries brasileiros, foi empregada novamente a ANOVA. Os dados evidenciaram diferença estatisticamente significativa na Escala de Motivação e Estratégias para o Aprendizado considerando-se $F(2,217)=6,796, p=0,001$. Pelo teste post-hoc de Tukey foi possível identificar que a diferença estava entre o $2^{\circ}$ ano $(M=33,5)$ e a $4^{a}$ série $(M=33,1)$. A diferença entre $\circ 2^{\circ}$ ano e a $4^{a}$ série, estatisticamente significante $(p=0,000)$, revelou que a maioria dos dados obtidos nessa pesquisa evidenciou: quanto mais o aluno avança nos anos escolares, tanto menor é seu nível de motivação para aprender.

Cabe destacar também que o percentual de diferença obtido nessa mesma escala por alunos chilenos matriculados no $2^{\circ}$ e no $4^{\circ}$ ano foi de $0,3 \%$ enquanto que a diferença entre o $2^{\circ}$ ano e a $4^{a}$ série no Brasil foi de $4,05 \%$. Um fator que merece destaque é a diferença de idade entre os anos/séries em que a diferença na escala em questão foi estatisticamente significativa. Enquanto no Chile a diferença de idade é de 2 anos, no Brasil essa diferença é de 3 anos. 
No caso da motivação extrínseca por regulação externa a ANOVA mostrou diferença, tendo em vista $F(3,256)=17,167, p=0,000$. Com o teste post-hoc de Tukey foi possível aferir diferença $(p=0,003$ e $p=0,001$, respectivamente) entre $\circ 1^{\circ}$ ano $(M=14,3)$ e o $3^{\circ}$ ano $(M=8,6)$ e $4^{a}$ série $(M=7,9)$. Também houve diferença $(p=0,036$ e $p=0,000$, respectivamente) entre $\circ 2^{\circ}$ ano $(M=13,2)$ e o $3^{\circ}$ ano e a $4^{a}$ série. A análise dos dados revela que $01^{\circ}$ ano obteve a maior pontuação na subescala motivação extrínseca por regulação externa, pontuação quase duas vezes superior à obtida pelos alunos da $4^{\mathrm{a}}$ série.

Um fator que também chama a atenção ao se analisarem diferenças por ano/ série brasileiro na pontuação na subescala motivação extrínseca por regulação externa é que tanto a $3^{\mathrm{a}}$ série como a $4^{\mathrm{a}}$ série apresentaram diferença estatisticamente significativa $(p=0,000)$ em relação ao $1^{\circ}$ ano, enquanto que na realidade chilena o $1^{\circ}$ ano apresentou diferença estatisticamente significativa somente em relação ao $4^{\circ}$ ano $(p=0,040)$. A realidade investigada nas escolas chilenas revelou que o $2^{\circ}$ ano é que possui diferença estatisticamente significativa $(p=0,000)$ em relação ao $3^{\circ}$ ano e ao $4^{\circ}$ ano.

A ANOVA indicou ainda diferença na motivação extrínseca por regulação introjetada, face $F(3,256)=16,755$, $p=0,000$. O teste post-hoc de Tukey possibilitou ver que as diferenças ( $p=0,000, p=0,032$ e $p=0,000$, respectivamente) estavam entre o $1^{\circ}$ ano $(M=16,3)$ e a $4^{a}$ série $(M=10,4), 2^{\circ}$ ano $(M=14,7)$ e a $4^{\text {a }}$ série e o $3^{\circ}$ ano $(M=12,9)$ e a $4^{\text {a }}$ série. Quanto às diferenças verificadas no Brasil, por ano/série, na pontuação da subescala motivação extrínseca por regulação introjetada, ficaram evidentes tais diferenças entre a $4^{a}$ série e todos os anos escolares que a antecedem, numa média de 4,3 pontos.

Por fim, também pela ANOVA levantou-se diferença na motivação intrínseca, considerando $F(3,259)=5,769, p=0,001$. O teste post-hoc de Tukey levantou diferenças $(p=0,003$ e $p=0,010$, respectivamente) entre o $1^{\circ}$ ano $(M=23,5)$ e a $4^{a}$ série $(M=21,4)$ e o $2^{\circ}$ ano $(M=23,7)$ e a $4^{a}$ série. No que se refere à motivação intrínseca, evidenciou-se que os dois primeiros anos do ensino fundamental brasileiro apresentaram diferença estatisticamente significativa em relação ao último ano, o que revela uma diminuição nesse nível de motivação para aprender, com o avanço nos anos escolares.

\section{Discussão e Conclusão}

A verificação da motivação para aprender de alunos brasileiros e chilenos, revelada pelos dados levantados segundo a Escala de Motivação e Estratégia para o Aprendizado, demonstrou que ambos apresentaram boa qualidade motivacional para aprender. No que se refere aos dados obtidos com o Questionário de Continuum Infantil, as duas realidades culturais investigadas apresentaram resultados muito similares, revelando semelhante qualidade motivacional.

Pelos resultados apresentados, percebe-se que as crianças das duas realidades culturais parecem atender às quatro perspectivas básicas para a compreensão do homem intrinsecamente motivado: competência, curiosidade, autonomia e motivação internalizada, como afirmam Martini e Boruchovitch (2004), visto que $98 \%$ das crianças que responderam à subescala da motivação intrínseca, nos dois países, obtiveram pontuação superior a 23 pontos, num total máximo de 25. Este dado corrobora a afirmação de Martinelli e Genari (2009) quando atestam que a motivação intrínseca caracteriza o início da escolarização.

Com relação a verificação de eventuais diferenças, na motivação para aprender, entre as crianças das duas realidades culturais investigadas, os resultados obtidos conforme a Escala de Motivação e Estratégias para o Aprendizado, revelaram que os alunos chilenos são mais motivadas para aprender do que os alunos brasileiros. Um dos possíveis fatores responsável por tal resultado é o investimento em educação. De acordo com Donoso e Donoso (2009), 15,3\% do PIB chileno é destinado à educação, num Continuum de investimento do Estado no setor educacional, enquanto que no Brasil, atualmente, este percentual não chega a $5 \%$.

Outro quesito ao qual se pode atribuir o grau mais elevado da motivação para aprender das alunas chilenas em comparação com os alunos brasileiros, é a jornada escolar. No Chile, os alunos da educação básica possuem uma jornada única. Passando o dia todo na escola, os vínculos com esse espaço e com os elementos que o constituem se tornam mais estreitos, satisfazendo a necessidade de pertencimento, uma das três necessidades psicológicas básicas que, segundo a Teoria da Autodeterminação, gera motivação.

Um ponto que se evidenciou junto aos resultados alcançados e que também merece ser comentado, trata do indíces que indicaram que os chilenos são mais motivados intrinsecamente do que os brasileiros e estes, por sua vez, apresentam-se mais motivados extrinsecamente, por regulação identificada, que os chilenos. Quanto ao fato dos alunos brasileiros se revelarem extrinsecamente motivados por regulação identificada, pode-se atribuir a preocupação da família e da sociedade contemporânea com relação aos estudos como garantia de um futuro melhor.

Foi possível também averiguar nesta pesquisa, a diferença na motivação para aprender, entre alunos do $1^{\circ}$ e $4^{\circ} \mathrm{ano} / 4^{\mathrm{a}}$ série, em ambas as realidades culturais. Tal diferença confirma o que atestam Martinelli e Genari (2009), quando destacam que, no decorrer do percurso escolar, os alunos agem muito mais por motivação extrínseca do que por motivação intrínseca. Bzuneck (2009) assevera que o decréscimo do nível de motivação pode ser também associado a problemas não resolvidos nas séries anteriores e/ ou a influência que o aluno recebe das novas exigências em razão dos diferentes tipos de disciplinas, aliadas às suas características evolutivas.

As diferenças estatisticamente significativas, quanto à motivação para aprender, constatadas nas duas realidades culturais investigadas, sugerem atividades de intervenção junto aos professores e às crianças. Conclui-se, portanto, que facultar ao professor o acesso ao conhecimento his- 
toricamente construído contribui para que ele reconheça e exerça eficazmente seu indispensável papel na motivação para aprender. Cabe destacar, nesse aspecto, a necessidade da criação e a efetivação de políticas educacionais que favoreçam o aperfeiçoamento profissional dos professores. Quanto às crianças, proporcionar-Ihes atividades que satisfaçam sua necessidade de competência, de autonomia e de pertencimento é imprescindível para que tenham um padrão motivacional de mais qualidade.

\section{Referências}

Bzuneck, J.A. (2009). A motivação do aluno: aspectos introdutórios. In: Boruchovith, E.; Bzuneck, J. A. (Orgs.), A Motivação do Aluno: Contribuições da Psicologia Contemporânea (pp. 9-36). Petrópolis: Vozes.

Bzuneck, J.A. \& Guimarães, S.É.R. (2010). A promoção da autonomia como estratégia motivacional na escola: uma análise teórica e empírica. In: Boruchovitch, E.; Bzuneck, J.A.; Guimarães, É.R. (Orgs.), Motivação para aprender (pp. 43-70). Petrópolis, RJ: Vozes.

Bzuneck, J.A., Megliato, J.G.P., \& Rufini, S.É. (2013). Engajamento de adolescentes nas tarefas escolares de casa: uma abordagem centrada na pessoa. Psicologia Escolar e Educacional, 17(1), 151-161.

Chen, B., Vansteenkiste, M., Beyers, W., Boone, L., Deci, E.L., Van der Kaap-Deeder, J., \& Ryan, R. M. (2015). Basic psychological need satisfaction, need frustration, and need strength across four cultures. Motivation and Emotion, 39(2), 216-236.

Deci, E.L. \& Ryan, R.M. (2000). The "what" and "why" of goal pursuits: human needs and self-determination of behavior. Phychological Inquiry, 11, 227-268.

Donoso, S. \& Donoso, G. (2009). Políticas de gestión de la educación pública escolar en Chile (1990 -2010): una evaluación inicial. Ensaio: Avaliação e Políticas Públicas em Educação, 17. Recuperado: 17 mar. 2017. Disponível: http://www.redalyc.org/ $\mathrm{html} / 3995 / 399537966003 /$.

Fernandes, D.C. \& Silveira, M.A. (2012). Evaluación de la motivación académica y la ansiedad escolar y posibles relaciones entre ellas. Psico USF, 17(3), 447-455.

Fernandez-Gonzalez, O.M., Martinez-Conde Beluzan, M., \& Melipillan Araneda, R. (2009). Estrategias de aprendizaje y autoestima: su relacion con la permanencia y desercion universitaria. Estudos Pedagógicos (Valdivia), 35(1), 27-45.

Gniewosz, B., Eccles, J.S., \& Noack, P. (2015). Early adolescents' development of academic self concept and intrinsic task value: The role of contextual feedback. Journal of Research on Adolescence, 25(3), 459-473.
Guimarães, S.E., Bzuneck, J.A., \& Oliveira, K.L. (2011). Estudo de validação de uma medida de avaliação da motivação para alunos do ensino fundamental. Psico-USF, 16 (1), 1-9.

Maieski, S., Oliveira, K.L.D., \& Bzuneck, J.A. (2013). Motivação para aprender: o autorrelato de professores brasileiros e chilenos. Psico USF,18(1), 53-64.

Martinelli, C.S. (2014). Um estudo sobre desempenho escolar e motivação de crianças. Educar em revista, (53), 201-216.

Martinelli, S.C. \& Genari, C.H.M. (2009). Relações entre desempenho escolar e orientações motivacionais. Estudos de Psicologia, 14(1).

Martini, M.L. \& Boruchovitch, E. (2004). A teoria da atribuição de causalidade: contribuições para a formação e atuação de educadores. Campinas, SP: Editora Alínea.

Muñoz, C. \& Valenzuela, J. (2014). Escala de motivación por el juego (EMJ): estudio del uso del juego en contextos educativos. RELIEVE-Revista Electrónica de Investigación y Evaluación Educativa, 20(1).

Oliveira, K.L., Maieski, S., Beluce, A.C., Oliveira, G.T., \& Santos, A. (2014). Propriedades psicométricas de uma escala de motivação e estratégias para aprender. Avaliação Psicológica, 13(1), 95-103.

Osborne, J.W. \& Jones, B.D. (2011). Identification with academics and motivation to achieve in school: How the structure of the self influences academic outcomes. Educational Psychology Review, 23(1), 131-158.

Paulino, P., Sá, I., \& Silva, A. L. (2016). Crenças e estratégias da motivação na aprendizagem: Desenvolvimento de uma escala. Psychologica, 58(1), 65-87.

Perassinoto, M.G.M., Boruchovitch, E., \& Bzuneck, J.A. (2013). Estratégias de aprendizagem e motivação para aprender de alunos do Ensino Fundamental. Avaliação Psicológica, 12(3), 351 359.

Pereira, F. O. (2015). Especificidades do rendimento, aptidão e motivação escolares em alunos com dificuldades de aprendizagem. Psicologia Escolar e Educacional, 19(3), 525-536.

Pintrich P.R. \& Schunk, D.H. (2002). Motivation in education - theory, research and applications. New Jersey: Merril Prentice Hall.

Reeve, J., Deci, E.L., \& Ryan, R. M. (2004). Self-determination theory: A dialectical framework for understanding socio-cultural influences on student motivation. In: McInerney, D.M.; Van Etten, S. (Orgs.), Big theories revisited (pp. 31-60). Greenwich, CT: Information Age Press.

Rosas, R., Perez-Salas, C.P., \& Olguin, P. (2010). Pizarras interactivas para un aprendizaje motivado en niños con paralisis cerebral. Estudos Pedagógicos (Valdivia), 36(1), 191-209. Recuperado: 15 mar. 2017. Disponivel: https://goo.gl/oyuPUk. 
Rufini, S.E., Bzuneck, J.A., \& Oliveira, K.L. (2011). Estudo de validação de uma medida de avaliação da motivação para alunos do ensino fundamental. Psico-USF, 16, 1-9.

Silva-Peña, I.,García, K.B.,Tapia, L.C., Llancafil, J.D., \& Carreño, J.V. (2013). Sentido de la Escuela para niños y niñas mapuche en una zona rural. Polis (Santiago), 12(34), 243-258.

Valenzuela, C.M., Torres, S.F., Quintul, P.S., Pérez, S.S., Rodríguez, M.P., \& Carreño, J.V. (2012). Características psicométricas de una escala para caracterizar la motivación por la lectura académica. Revista electrónica de investigación educativa,14(2), 118-132.

Villalobos, M.V.P., Mujica, A.D., González-Pienda, J.A., Núñez Pérez, J.C., \& Rosário, P. (2009). Escala de metas de estudio para estudiantes universitarios. Interamerican Journal of Psychology, 43(3), 449-455.
Wigfield, A., Eccles, J.S., Fredricks, J., Simpkins, S., Roeser, R., \& Schiefele, U. (2015) Development of achievement motivation and engagement. In: Lerner, R. M.; Garcia Coll C.; Lamb, M. (Orgs.) Handbook of child psychology (Vol. 3, pp. 657-700). New York: JohnWiley \& Sons Inc.

Zambon, M.P. \& Rose, T.M.S. (2012). Motivação de alunos do ensino fundamental: relações entre rendimento acadêmico, autoconceito, atribuições de causalidade e metas de realização. Educação e Pesquisa, 38(4), 965-980.

Zenorini, R.D.P.C., Santos, A.A.A.D., \& Monteiro, R.D.M. (2011). Motivação para aprender: relação com o desempenho de estudantes. Paidéia, 21(49), 157-164.

Recebido em: 07 de outubro de 2016 Aprovado em: 13 de fevereiro de 2017

\section{Sobre as autoras}

Sandra Maieski (irmsandramaieski@gmail.com)

Mestre em Educação pela Universidade Estadual de Londrina. Gestora Pedagógica do Colégio Mãe de Deus de Londrina - PR.

Katya Luciane de Oliveira (katyauel@gmail.com)

Mestre em Psicologia pelo Programa de Estudos de Pós-graduação Stricto-Sensu em Psicologia da Universidade São Francisco. Doutora em Psicologia, Desenvolvimento Humano e Educação pela Faculdade de Educação da Unicamp. Docente do curso de Psicologia, do Programa de Mestrado em Psicologia e do Programa de Mestrado e Doutorado em Educação da Universidade Estadual de Londrina. Bolsista Produtividade Nível 2/CNPq.

Andrea Carvalho Beluce (andreabeluce@gmail.com)

Doutoranda em Educação pela Universidade Estadual de Londrina (UEL). Mestre em Educação pela UEL. Gestora Pedagógica do Ambiente Virtual de Aprendizagem da Prefeitura Municipal de Londrina (AVA/PML) e coordenação da Escola de Governo da PML, Londrina - PR.

Sueli Édi Rufini (rufinisueli@gmail.com)

Doutora em Educação pela Universidade Estadual de Campinas - Professora associada da UEL, docente do Mestrado em Educação. Universidade Estadual de Londrina. Londrina - PR. 